\title{
A short introduction to attachment and attachment disorder (2nd ed.)
}

\author{
Colby Pearce \\ Jessica Kingsley Publishers, London and Philadelphia, 2017 \\ ISBN 978178592058 5; elSBN 978178450315 4, pp.160, \\ paperback, NZD30.43
}

I have an enduring interest in the role of attachment in child, adolescent and adult mental health. Whether a person relates to the world as safe or unsafe underpins and influences every relationship they have. Attachment then, is fundamental to their mental wellbeing in a way that no other single phenomenon could be.

Given the plethora of books on how attachment can go wrong and how to mitigate harm, what does Colby Pearce add to the literature that is new and different?

Pearce is a Clinical Psychologist in private practice in Adelaide. He has worked with children, teens and families for over 20 years. This book introduces us to the CARE (Consistency, Accessibility, Responsiveness and Emotional connectedness) model for fostering sound attachment.

One of Pearce's gifts lies in his ability to use simple analogies to explain complex concepts. "The Tale of Four Mice" in his Prologue is a poignant reminder of how the meeting (or not) of even a basic need can determine mental health outcomes. If you wanted to distil the complexity of attachment in all its forms into one simple fable, The Tale of Four Mice does so beautifully.

His book is divided into four chapters: Understanding Attachment and the Influence of Parental Care; A Short Introduction to Attachment Disorder; CARE to Promote Attachment Security and Treating Attachment Insecurity and Disorder: Fundamental Requirements for Effective Treatments.
He provides a potted history of attachment with the usual suspects-Bowlby, Ainsworth, Harlow, Erikson-and a useful glossary. Pearce delivers with a straightforward and easy-to-follow writing style, covering the main bases that one would expect from a "short introduction".

Is the world a safe place to explore and form relationships in or is it a dangerous place where exploration and relationships are fraught with hurt and disappointment?

Each chapter has a useful summary at the end and we follow the story of Matthew-a young boy in care-to illustrate the CARE model, which is used to promote secure attachment.

We learn why attachment is so important, the concept of Self and relatedness to others and the role of resilience.

We then move onto such attachment disorders as Reactive Attachment Disorder (RAD) and Disinhibited Social Engagement Disorder (DSED).

So far, so Attachment 101.

However, when Pearce looks at elevated emotional arousal (pp.48-49), he uses the novel example of how a car's petrol engine runs-idling at a particular speed without use of the accelerator. However, there are those whose engines can go from idle to red-line point very quickly. Or as it is described colloquially by caregivers in my line of work, "going from 1 to 100 in a nano-second". 
This analogy is useful to describe the physiological effect of emotional arousal which can occur too fast for the person who has been triggered to control. Pearce then goes on to make an unequivocal statement: "[a]rousal management is a key aspect of the care and management of children who have an attachment disorder" (p. 52). I only disagree in as far as I believe it to be the key aspect.

This book contained a number of "lightbulb" moments for me, where I saw something from a slightly different angle, which added to depth of my understanding.

For example, Pearce explains the controlling and manipulative behaviour of those with an attachment disorder as typically taking the form of angry, destructive behaviours and charming and seductive behaviours or a combination of these. He points out that almost from birth, infants use the ageappropriate displays of crying and smiling, to gain the attention of their carers. "It follows that children who are preoccupied with accessibility to needs provision are likely to use these infant strategies (i.e., charming smiles and screaming tantrums) (p. 139).

The author goes on to make what I consider to be one of the crucial truisms of all human behaviour: "nobody does anything for no reason" (p. 86). This is, of course, the crux of understanding disordered attachment behaviour-all behaviour (no matter how dysfunctional, bizarre or apparently irrational) serves a purpose. As a carer, a therapist or even a parent, it is our job to work out what that purpose might be.

Then shortly afterwards, the second truism: "in order to be heard, you first need to listen" (p. 88).

For me, the greatest magic lies in Chapter Three-CARE to Promote Attachment Security.
Here Pearce explains that "[ $t]$ he most commonly reported behaviour among the respondent carers was that the children were demanding" (p. 80; his italics). In my experience as a carer assessor, there seems to be a fear among carers that meeting a child's needs when they demand it, will result in an avalanche of unquenchable demands that will overwhelm them as carers. Or put another way, they will be rewarding and thus encouraging "bad behaviour". Yes and no.

Not to give away too many of the book's secrets, but the author lays this myth to rest very efficiently in Chapter Three. Pearce then provides step-by-step instructions of three of the simplest and most brilliant techniques I have seen to stem the tide of neediness to a negligible trickle.

There is his effective sleep routine, his clever use of the game of Uno to encourage empathy and his simple token system to put a healthy sense of control into the hands of the young person to both reduce emotional arousal and encourage positive attachment.

The final and fourth chapter covers therapeutic treatment and management, using CARE principles and attachment-based play.

This book should be essential reading for anyone who has a foster child or is considering fostering one. It got me so excited that I longed to be back in that field and using Pearce's text as a handbook for any of my carers who have said "But why does s/ he .... how can I stop it?"

We re-visit Matthew for the last time in the final chapter and I took huge delight in the playfulness of the therapist, their sensitive attunement to Matthew's emotional needs and Matthew's own happier ending. 